\title{
Endometrial and Subendometrial Vessels in Cases of Unexplained Infertility (Case Control Study)
}

\author{
MOHAMED E. ALI, M.D.*; HEBA A. ELSWAH, M.D.*; AYMAN A. HASSAN, M.D.*; \\ YASSMIN T. EL-SHEWEY, M.D. ${ }^{* *}$ and DALIA A. NOUR, M.Sc.* \\ The Departments of Obstetrics \& Gynecology* and Chemical Pathology**, Faculty of Medicine, Cairo University
}

\begin{abstract}
Background: Infertility defined as failure to conceive after 12 months of unprotected regular intercourse. Unexplained infertility describes couples with infertility in whom standard investigations including semen analysis, tests of ovulation, and tubal patency have no gross abnormality.

Aim of Study: To evaluate the endometrial and subendometrial blood flow in mid-luteal phase after measuring serum progesterone level in unexplained infertility patients and compare those parameters with fertile women in order to reveal the role of the uterine perfusion in unexplained infertility.

Patients \& Methods: In this study, we collected 100 participants presented to the outpatient clinic in Kasr El-Aini maternity hospital, we classify them into two groups: Group A: 50 women presented with unexplained infertility either primary or secondary (the case group). Group B: 50 women who had no history of infertility and at least have one child who came for any gynecological procedure (the control group) Primary outcome measures (VI) (FI) \& (VFI) of endometrial and subendmetrial areas using (VOCAL) in mid luteal phase after measurement of serum progesterone level in both groups.

Results: As regards endometrial vascularity index (VI), it was higher in control group $(0.64 \pm 0.05)$ than in case group $(0.51 \pm 0.09)$, Sub endometrial (VI) also was higher in control group $(2.34 \pm 0.13)$ than in case group $(1.92 \pm 0.22)$, endometrial flow index (FI), it was higher in control group (29.26 \pm 1.98$)$ than in case group $(24.47 \pm 4.19)$, sub endometrial flow index $(\mathrm{FI})$, it was higher in control group $(36.29 \pm 3.10)$ than in case group (30.52 \pm 2.52$)$, endometrial vascular flow index (VFI), it was higher in control Group $(0.36 \pm 0.05)$ than in case group $(0.25 \pm 0.04) \&$ subendometrial vascular flow index (VFI), it was higher in control group $(1.13 \pm 0.25)$ than in case group $(0.83 \pm 0.07)$ all of that are statistically significant. As regards to serum progesterone level it was higher in control group $(12.87 \pm 2.47)$ than in case group $(12.66 \pm 3.17)$ which was statistically insignificant.
\end{abstract}

Conclusion: From our study we found that impairment of uterine perfusion could have a role in cases of unexplained infertility.

Correspondence to: Dr. Mohamed E. Ali, The Department of Obstetrics \& Gynecology, Faculty of Medicine, Cairo University
Key Words: Unexplained infertility - Endometrial blood flow by VOCAL - Subendometrial blood flow by VOCAL).

\section{Introduction}

INFERTILITY is considered when failure to conceive after one year of unprotected regular intercourse. $17 \%$ of the couples may complain of infertility, with $40 \%$ the female pathology is the cause [1].

Infertility is classified into primary, in women who have never get pregnant, and secondary, in women who have at least one pregnancy. This review will deal with unexplained infertility which represents $10 \%$ to $20 \%$ of infertility cases [2]

Unexplained infertility is a term used to describe couples with no abnormality revealed with the standered investigations.

Whole investigations including semen analysis, tests of ovulation, and tubal patency have failed to detect any gross abnormality [3].

Uterine perfusion one of the factors that regulate endometrial receptivity [4].

Abnormal uterine perfusion may be a contributing factor to the pathology of infertility especially in couples with unexplained infertility. Pulsed Doppler is an excellent tool for examining the female reproductive system. It is a non-invasive method to assess the uterine perfusion [5]

It has been proved that 3-D ultrasound is a highly reproducible technique. With 3-D ultrasound, a volume of a region of interest can be acquired and stored. 3-D ultrasound, allows for a whole assessment of relevant vessels and quantitative 
assessment of vessel density and perfusion within a specified area. A whole evaluation is then possible for endometrial and subendometrial vascularization [6].

Transvaginal ultrasonography with colour Doppler imaging and pulsed Doppler spectral analysis have been used to evaluate the endometrial and subendometrial vascularization through detecting vascularization index (VI), flow index (FI), and vascularization flow index (VFI).

The aim of this study is to evaluate the midluteal phase serum progesterone level with evaluation of endometrial and subendometrial blood flow in unexplained infertility patients and compare those parameters with fertile females in order to reveal the possible role of the uterine perfusion in the infertility etiopathogenesis.

\section{Patients and Methods}

The study was performed during the period of two years from (June 2013) till (2015) we had 100 participants presented to the Outpatient Clinic in Kasr El-Aini Maternity Hospital; we classified them into two groups:

- Group A: 50 participants presented to infertility clinic with unexplained infertility either primary or secondary (the case group).

- Group B: 50 participants presented to gynecological clinic without any history of infertility and at least had one child who came for gynecological procedure (the control group).

At the time of initial recruitment, the purpose of the study was adequately explained to each participant. Consent was taken complete history was taken and serum progesterone level was sampled at mid luteal phase then transvaginal power Doppler ultrasonography was performed to all patients in luteal phase (day 21-22) of cycle to detect blood flow in endometrial and subendometrial area presented by the indices vascularization index (VI), flow index (FI), and vascular flow index (VFI). The indices between the two groups were compared.

\section{Inclusion criteria for the infertility group:}

- Age between 18-40 years old.

- Infertility either primary or secondary and the duration of infertility.

- Investigations were done:

- Semen analysis to exclude male factor.

- Hormonal profile (FSH, LH, E2 \& prolactin).
- HSG revealed no congenital anomalies, masses, or adhesions within the uterine cavity and patent fallopian tubes, and transvaginal ultrasonography revealed adequate secretory endometrium within the luteal phase.

Inclusion Criteria for the control group:

- Age between 18-40 years old.

- Parous women in mid luteal phase.

- No hormonal contraception.

- No IUCD in place.

Exclusion criteria for both groups:

- Infertility due to ovarian factor.

- Infertility due to tubal disease.

- Infertility due to uterine or cervical cause.

- Infertility due to male factor.

- Pregnant woman.

- Patient who refuse to participate in the study.

Steps and methods:

Patients to be recruited gave an informed consent and were subjected to:

1- Complete history taking:

- Personal history.

- Menstrual history.

- Obstetric history.

- Past medical and surgical history.

- Drug history.

2- General, abdominal and pelvic examinations:

- General examination:

- General examination: Body decuibetis, signs of hirsiutism and signs of thyroid disease.

- Breast examination for swelling or nipple discharge.

- Abdominal examination: Excludes any pelvi abdominal mass.

- Complete pelvic examination.

\section{3- Investigations: (infertility group):}

- Semen analysis to exclude male factor of infertility.

- Hormonal profile at 3 rd day of the cycle (FSH, LH, Estradiol and prolactin).

- HSG to confirm the patency of the fallopian tubes, and to exclude any structural abnormality of the uterus. 
- Serum progesterone level at 21 st - $22 n d$ day of the cycle:

- The sample is collected from patient.

- Centrifugation is done to obtain at least 1$\mathrm{ml}$ of serum.

- Serum progesterone level is a radioimmunoassay performed with in-house reagents. The radioimmuno-assay technique is based on the competitive binding of the serum progesterone and a radio labeled progesterone preparation. They compete for binding to an antibody specific for progesterone. The antibody-bound radio labeled progesterone is separated and the quantity is determined by counting in a gamma spectrometer. Results for the unknown are read from a curve prepared by plotting results for a set of known standards. Sera with pre-determined concentrations are included in every extraction procedure and assayed for quality control purposes).

4- Type of ultrasound: We use the scanner (Voluson $730 \mathrm{PRO}$ ) with 7.5 MHZ endocavitary transducer with pulsed colour Doppler and 3D facility in examination of our participants.

\section{Technique of transvaginal ultrasound:}

1-Empty the urinary bladder and prepare the patient for ultrasound examination.

2- The examination table: For the scanning procedure an in-line transducer probe (a probe that has an end firing scan head with its shaft and handle on the same axis), so a flat ultrasound examination table was appropriate. The elevated thighs enabled free movement of the probe in the horizontal plane by the operator.

3- The equipment and the transducer: All the patients were subjected to the following:

- The vaginal probe was covered with a condom containing a small amount of gel. The gel ensured good contact between the transducer and the overlying condom. Care was taken to avoid trapping of any air bubbles, which might have created unwanted artifacts on the screen. Cross infection was prevented by the use of probe cover and disinfectants.

- Transvaginal probe will be inserted into the vagina and placed in the anterior fornix. Both internal cervical os and the external one are identified, and uterine examination will be performed to rule out any uterine anomaly that might interfere with pregnancy such as uterine septum, bicornuate uterus, and uterine myomas and to rule out any abnormalities in the secretory endometrium.

- The probe will be moved 90 degree to have transverse section in the uterus then moved laterally to get the right ovary in the ovarian fossa which will be identified then the left one will be identified by the same way.

- A longitudinal view of the uterus was then obtained then power Doppler mode was activated, subsequently the region of interest was defined by a movable sector on the screen which was placed over the endometrium and subendometrial area (where $5 \mathrm{~mm}$ of the endometrial borders were included), virtual organ computer aided analysis (VOCAL) was used to calculate the endometrial volume. The histogram facility was used to generate the vascularization index (VI) characterized vessel density, the flow index (FI) described the intensity of blood flow, and the vascular flow index (VFI) assessed both vascularity and perfusion as shown in Figs. $(1,2)$.

\section{Statistically analysis:}

Quantitative variables are expressed as mean \pm standard deviation $( \pm$ S.D) and comparisons were performed using the $t$-test for independent samples if the samples were normally distributed or by the Mann-Whitney test otherwise. The significance level was 0.05 and $p$-values less than 0.05 were considered significant. Binary logistic regression analysis model has been performed to predict a categorical variable from a set of predictor variables.

Data were statistically described in terms of mean \pm standard deviation $( \pm$ S.D $)$, median and range, or frequencies (number of cases) and percentages when appropriate. Comparison of numerical variables between the study groups was done using Student $t$ test for independent sampless. For comparing categorical data, Chi square $\left(\chi^{2}\right)$ test was performed. Exact test was used instead when the expected frequency is less than 5. $p$-values less than 0.05 was considered statistically significant. All statistical calculations were done using computer program SPSS (Statistical Package for the Social Science; SPSS Inc., Chicago, IL, USA) release 15 for Microsoft Windows. 


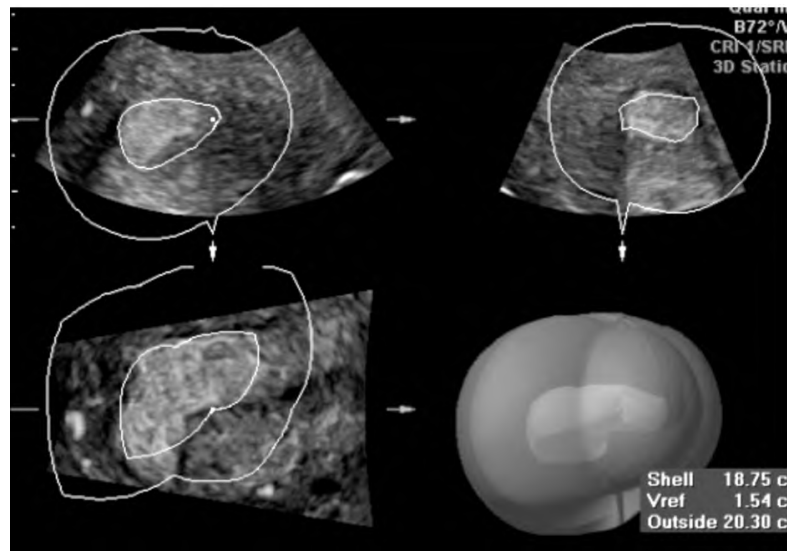

Fig. (1): Obtaining endometrial and subendometrial vascularity volume by $3 \mathrm{D}$ power Doppler.
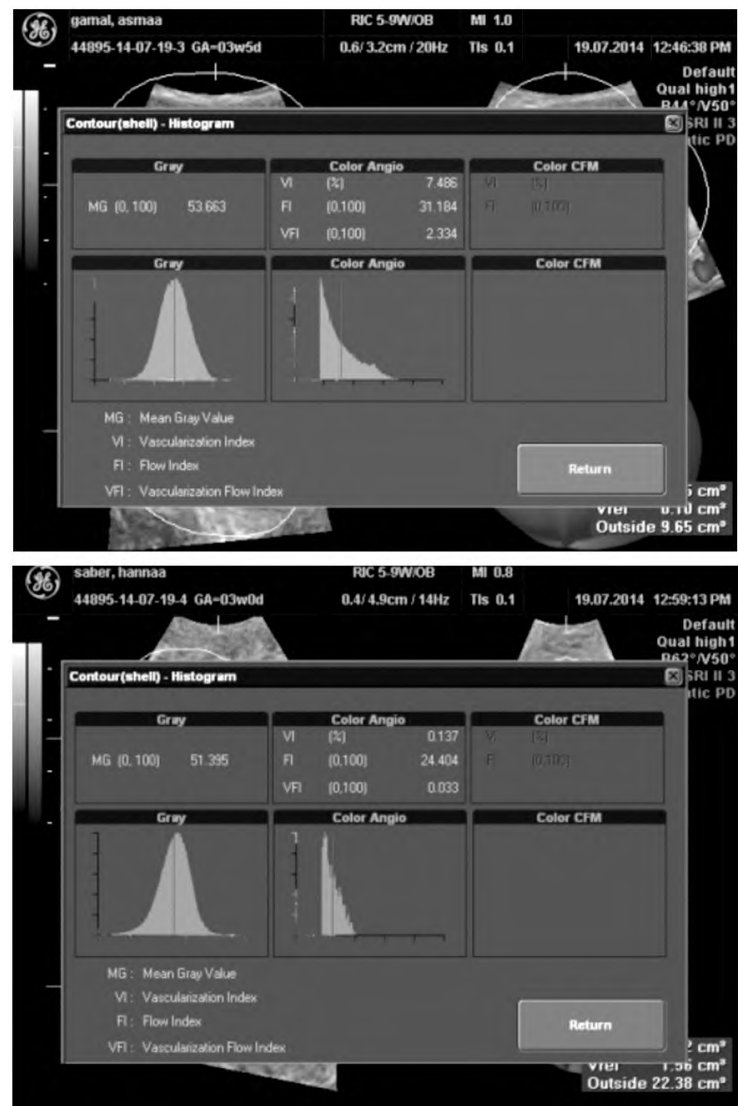

Fig. (2): Calculation of vascular indices by 3D power Doppler using VOCAL method.

\section{Results}

From our study we got the following results: The age in control group $(27.72 \pm 5.86)$ was higher than case group $(26.56 \pm 5.32)$ but with no statistical significance ( $p$-value 0.302$)$. Gravidity was higher in control group $(2.30 \pm 1.22)$ than in case group $(1.22 \pm 1.40)$ which was statistically significant, $(p$ value 0.001$)$. Parity was higher in control group $(2.04 \pm 1.14)$ than in case group $(0.92 \pm 1.26)$ which was statistically significant, $(p$-value 0.001$)$.
As regards endometrial vascularity index (VI), it was higher in control group $(0.64 \pm 0.05)$ than in case group $(0.51 \pm 0.09)$ which was statistically significant ( $p$-value 0.001). Subendometrial (VI) also was higher in control group $(2.34 \pm 0.13)$ than in case group $(1.92 \pm 0.22)$ which was statistically significant ( $p$-value 0.001).

As regards endometrial flow index (FI), it was higher in control group (29.26 \pm 1.98$)$ than in case group $(24.47 \pm 4.19)$ which was statistically significant ( $p$-value 0.001$)$. As regards sub endometrial flow index (FI), it was higher in control group $(36.29 \pm 3.10)$ than in case group $(30.52 \pm 2.52)$ which was statistically significant ( $p$-value 0.001$)$.

As regards endometrial vascular flow index (VFI), it was higher in control group $(0.36 \pm 0.05)$ than in case group $(0.25 \pm 0.04)$ which was statistically significant ( $p$-value 0.001 ). As regards subendometrial vascular flow index (VFI), it was higher in control Group $(1.13 \pm 0.25)$ than in case group $(0.83 \pm 0.07)$ which was statistically significant ( $p$-value 0.001$)$.

As regards to serum progesterone level it was higher in control group $(12.87 \pm 2.47)$ than in case group $(12.66 \pm 3.17)$ which was statistically insignificant ( $p$-value 0.718$)$.

Table (1): Comparison in age, gravidity and parity between case and control group.

\begin{tabular}{lccl}
\hline & $\begin{array}{c}\text { Control } \\
\text { group }(\mathrm{n}=50)\end{array}$ & $\begin{array}{c}\text { Case } \\
\text { group }(\mathrm{n}=50)\end{array}$ & $p$-value \\
\hline $\begin{array}{c}\text { Age: } \\
\text { Mean } \pm \text { S.D }\end{array}$ & $27.72 \pm 5.86$ & $26.56 \pm 5.32$ & $0.302(\mathrm{NS})$ \\
$\begin{array}{l}\text { Gravidity: } \\
\text { Mean } \pm \text { S.D }\end{array}$ & $2.30 \pm 1.22$ & $1.22 \pm 1.40$ & 0.001 \\
$\begin{array}{l}\text { Parity: } \\
\text { Mean } \pm \text { S.D }\end{array}$ & $2.04 \pm 1.14$ & $0.92 \pm 1.26$ & 0.001 \\
\hline
\end{tabular}

Table (2): Comparison of CS incidence between the case and control group.

\begin{tabular}{cccc}
\hline & Control $(\mathrm{n}=50)$ & Cases $(\mathrm{n}=50)$ & $p$-value \\
\hline 0 & $30(60 \%)$ & $37(74 \%)$ & \\
1 & $20(40 \%)$ & $13(26 \%)$ & $0.137(\mathrm{NS})$ \\
\hline
\end{tabular}

Table (3): Type of infertility in infertility group (primary or secondary).

\begin{tabular}{lcc}
\hline & Number & Percent (\%) \\
\hline Primary & 23 & 46 \\
Secondary & 27 & 54 \\
\hline
\end{tabular}


Table (4): Comparison in vascularization index (VI) between case and control group.

\begin{tabular}{lccc}
\hline & $\begin{array}{c}\text { Control } \\
(\mathrm{n}=50)\end{array}$ & $\begin{array}{c}\text { Cases } \\
(\mathrm{n}=50)\end{array}$ & $p$-value \\
\hline End VI & $0.64 \pm 0.05$ & $0.51 \pm 0.09$ & 0.001 \\
Sub end VI & $2.34 \pm 0.13$ & $1.92 \pm 0.22$ & 0.001 \\
\hline
\end{tabular}

Table (5): Comparison in flow index (FI) between case and control group.

\begin{tabular}{lccc}
\hline & $\begin{array}{c}\text { Control } \\
(\mathrm{n}=50)\end{array}$ & $\begin{array}{c}\text { Cases } \\
(\mathrm{n}=50)\end{array}$ & $p$-value \\
\hline End FI & $29.26 \pm 1.98$ & $24.47 \pm 4.19$ & 0.001 \\
Sub end FI & $36.29 \pm 3.10$ & $30.52 \pm 2.52$ & 0.001 \\
\hline
\end{tabular}

Table (6): Comparison in (VFI) between case and control group.

\begin{tabular}{lccc}
\hline & $\begin{array}{c}\text { Control } \\
(\mathrm{n}=50)\end{array}$ & $\begin{array}{c}\text { Cases } \\
(\mathrm{n}=50)\end{array}$ & $p$-value \\
\hline End VFI & $0.36 \pm 0.05$ & $0.25 \pm 0.04$ & 0.001 \\
Sub end VFI & $1.13 \pm 0.25$ & $0.83 \pm 0.07$ & 0.001 \\
\hline
\end{tabular}

Table (7): Comparison in serum progesterone level between case and control group.

\begin{tabular}{lccc}
\hline & $\begin{array}{c}\text { Control } \\
(\mathrm{n}=50)\end{array}$ & $\begin{array}{c}\text { Cases } \\
(\mathrm{n}=50)\end{array}$ & $p$-value \\
\hline Serum progesterone & $12.87 \pm 2.47$ & $12.66 \pm 3.17$ & $0.718(\mathrm{NS})$ \\
\hline
\end{tabular}

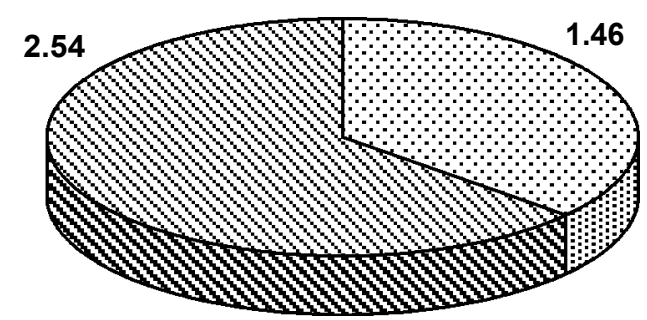

Fig. (3): Type of infertility in infertility group (primary or secondary).

\section{Discussion}

The main objective of this study was to determine whether women with unexplained infertility had an abnormality in vascularity of endometrial and subendometrial areas than women who had at least one live child and no history of infertility.

Kim et al., [7] reported the highest pregnancy rate in the group with lower resistance to blood flow in the uterine spiral arteries. This finding revealing the decrease in peripheral impedance in the uterine vasculature reflected by a low uterine artery PI was considered to be a consequence of increased blood flow and a sign of high tissue perfusion, and this might be an important prerequisite for successful pregnancy either natural or after IUI.

Some studies mentioned that a poor uterine perfusion might be one of the causes of unexplained infertility, Revel [8] however, few studies correlate unexplained infertility and Doppler flowmetry of the arteries responsible for uterine perfusion.

Inadequate blood flow would thus prevent implantation, although optimal uterine perfusion does not always mean pregnancy. In addition to this, high uterine resistance is observed in less than $10 \%$ of non-conception cycles, which suggests that this parameter is responsible for failure in implantation in very few cases Cacciatore et al., [9].

A study done by Ziegler et al., [10] has suggested that low levels of progesterone might cause the uterine vascular impedance to increase. Therefore, using the secretory endometrium as an inclusion criterion in the present study was intended to determine (however indirectly) whether hormonal action was adequate in our group of women with unexplained infertility, and to ensure that the examination occurred during the luteal phase.

It has been proposed to consider the endometrial and subendometrial area as a whole when the uterine perfusion is assessed by colour Doppler, since there is no difference between the endometrial and subendometrial blood flow with respect to the possibility of achieving pregnancy Chien LW et al., [11]

Compared the difference in uterine and spiral artery impedance to blood flow among women with unexplained and tubal infertility during spontaneous and gonadotropin-stimulated cycles in mid luteal phase and found that there were no differences in the uterine artery pulsatility index or peak systolic velocity during the spontaneous or the invitro fertilization cycle between the two groups [2]

Raine-Fenning et al., [12] observed that endometrial and sub-endometrial vascularity are significantly reduced in women with unexplained infertility but There were no differences in endometrial thickness or volume between the groups or in the plasma concentrations of estradiol or progesterone. These findings are in accordance with the results of our study.

Other studies showed that endometrial and subendometrial vascularity indices increased throughout the follicular phase, decreased to a 
nadir 2 days after follicular rupture and then increased again during the luteal phase. Endometrial and subendometrial volume increased rapidly during the follicular phase and then remained almost unchanged during the luteal phase [13]

All the studies show to demonstrate some changes in the endometrium and subendometrium using 3D ultrasound and they all proved that changes do occur and that 3D ultrasound is a reliable method to do this, more so than 2D ultrasound. Although, their main objective was to link these results to uterine receptivity in order to create the perfect environment for embryos to implant.

In conclusion, the presence of good uterine and endometrial blood flow is an important prerequisite for successful implantation and continuation of pregnancy. Those patients may have abnormalities in the uterine and endometrial blood flow. Despite these findings we could not find any cut off values that could predict the main cause of infertility in this group of which may be attributed to small sample size so larger prospective studies are needed aiming to confirm such results and reaching values that can accurately predict such cases.

\section{References}

1- HILL M.E., MOGHISSI K.S., MAGYAR D.M., HAYES M.F., ZADER J. and OLSON J.M.: Correlation of serum estradiol level and ultrasound monitoring to assess follicular maturation. Fertil. Steril., 46 (1): 42, 2005.

2- ISAKSSON R. and TIITINEN A.: Present concept of unexplained infertility. Gynecol, Endocrinol., 18: 278290, 2004.

3- STEER C.V., TAN S.L., MASON B.A. and CAMPBELL S.: Mid-luteal-phase vaginal Doppler assessment of uterine artery impedance in a sub-fertile population. Fertil. Steril., 61: 53-8, 1994.
4- GONG X., L1 Q., ZHANG Q. and ZHU G.: Predicting Endometrium Receptivity with parameters of spiral artery blood flow. Journal of Huazhong University of Science and Technology, 25: 335-8, 2005.

5- CHUN-KAI CHEN., HSIEN-MING WU and YUNGKUEI SOONG: Clinical application of ultrasound in Infertility: From Two-dimensional to Three-dimensional. Journal of Medical Ultrasound, Volume 15, Issue 2, pages, 126-133, 2007.

6- CAHILL D.J. and WARDLE P.G.: Management of infertility. BMJ., 325: 28-32, 2002.

7- A. KIM, J.E. HAN, T.K. YOON, S.W. LYU, H.H. SEOK and H.J. WON: Relationship between endometrial and subendometrial blood flow measured by three-dimensional power Doppler ultrasound and pregnancy after intrauterine insemination Fertil Steril, 94, pp. 747-752, 2010.

8- A. REVEL: Defective endometrial receptivity. Fertil. Steril., 97, pp. 1028-1032, 2012.

9- CACCIATORE B., SIMBERG N. and FUSARO P.: Transvaginal Doppler study of uterine artery blood flow in invitro fertilization embryo transfer cycles. Fert. Steril., 66: 130-134, 1996.

10- ZIEGLER D., BESSIS R. and FRYDMAN R.: Vascular resistance of uterine arteries: Physiological effects of estradiol and progesterone. Fertil. Steril., 55: 775-9, 1991.

11- CHIEN L.W., AU H.K., CHEN P.L., XIAO J. and TZENG C.R.: Assessment of uterine receptivity by the endometrial subendometrial blood flow distribution pattern in women undergoing in vitro fertilization embryo transfer. Fert. Steril., 78: 245-251, 2002.

12- RAINE-FENNING N.J., CAMPBELL B.K., KENDALL N.R., CLEWES J.S. and JOHNSON I.R.: Quantifying the changes in endometrial vascularity throughout the normal menstrual cycle with three dimensional power Doppler angiography. Human Reprod., 19: 330-338, 2004.

13- JOKUBKIENE L., SLADKEVICIUS P., ROVAS L. and VALENTIN L.: Ultrasound. Obstet. Gynecol., 27 (6): 672-9, 2006. 


\section{الأوعية الدموية فى أوعية بطانة الرحم والجزء من تحت بطانة الرحم الرئ فى حالات عدم الأنجاب الغير معروف الروف السبب}

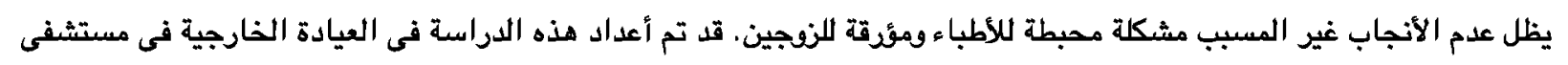

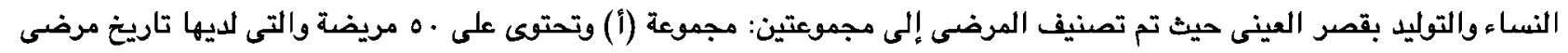

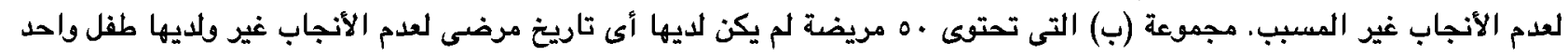

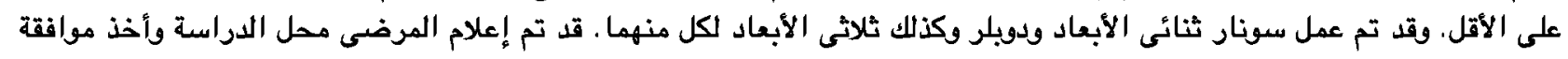

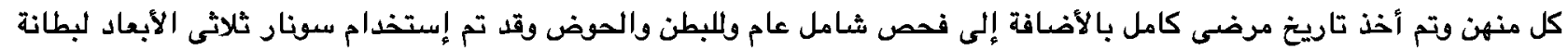

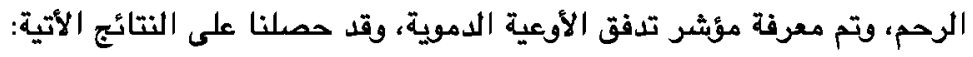

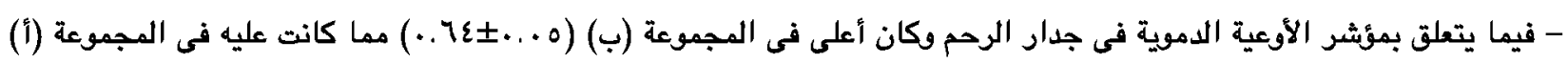

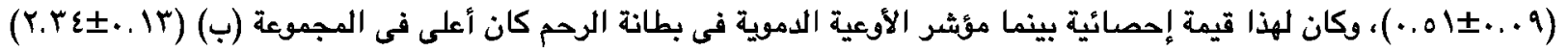

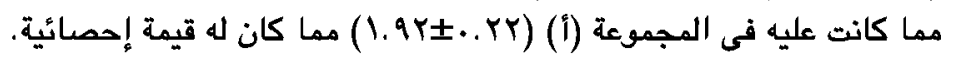

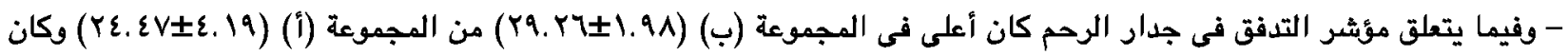

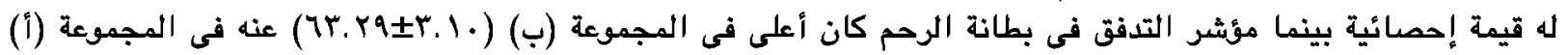
(r...ortr.or)

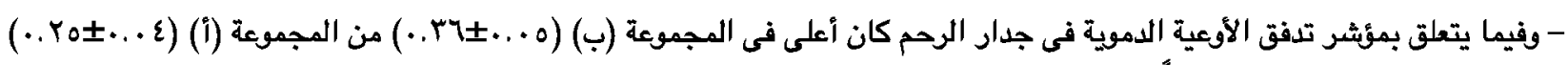

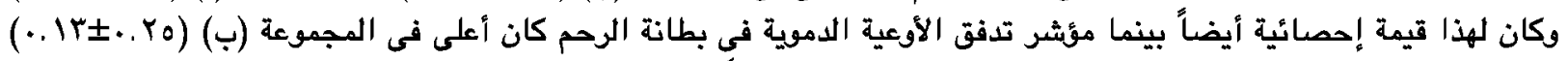

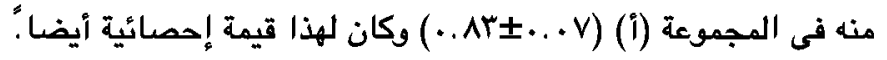
إذاً من رداستنا هذه تبين أنه من الممكن إفادة الحالات التى لديها التاريخ المرضى لعدم الأنجاب غير مسبب بتصسين تدفق الدم 